\title{
Blood-Brain Barrier Disruption and Oxidative Stress in Guinea Pig after Systemic Exposure to Modified Cell-Free Hemoglobin
}

Omer I. Butt, Paul W. Buehler, and Felice D'Agnillo

From the Laboratory of Biochemistry and Vascular Biology, Division of Hematology, Center for Biologics Evaluation and Research, Food and Drug Administration, Bethesda, Maryland

Systemic exposure to cell-free hemoglobin ( $\mathrm{Hb}$ ) or its breakdown products after hemolysis or with the use of Hb-based oxygen therapeutics may alter the function and integrity of the blood-brain barrier. Using a guinea pig exchange transfusion model, we investigated the effect of a polymerized cell-free $\mathrm{Hb}$ (HbG) on the expression of endothelial tight junction proteins (zonula occludens 1, claudin-5, and occludin), astrocyte activation, IgG extravasation, heme oxygenase (HO), iron deposition, oxidative end products (4-hydroxynonenal adducts and 8hydroxydeoxyguanosine), and apoptosis (cleaved caspase 3). Reduced zonula occludens 1 expression was observed after HbG transfusion as evidenced by Western blot and confocal microscopy. Claudin-5 distribution was altered in small- to medium-sized vessels. However, total expression of claudin- 5 and occludin remained unchanged except for a notable increase in occludin $\mathbf{7 2}$ hours after HbG transfusion. HbG-transfused animals also showed increased astrocytic glial fibrillary acidic protein expression and IgG extravasation after 72 hours. Increased $\mathrm{HO}$ activity and HO-1 expression with prominent enhancement of HO-1 immunoreactivity in CD163-expressing perivascular cells and infiltrating monocytes/macrophages were also observed. Consistent with oxidative stress, HbG increased iron deposition, 4-hydroxynonenal and 8-hydroxydeoxyguanosine immunoreactivity, and cleaved caspase- 3 expression. Systemic exposure to an extracellular $\mathrm{Hb}$ triggers blood-brain barrier disruption and oxidative stress, which may have important implications for the use of $\mathrm{Hb}$ based therapeutics and may provide indirect insight on the central nervous system vasculopathies associated with excessive hemolysis. (Am J Pathol 2011, 178:1316-1328; DOI: 10.1016/j.ajpath.2010.12.006)

Hemoglobin ( $\mathrm{Hb}$ )-induced neurotoxicity is a major pathophysiological feature of intracerebral $(\mathrm{ICH})$ and subarachnoid hemorrhage. ${ }^{1-3}$ The lysis of extravasated red blood cells exposes the central nervous system (CNS) to significant quantities of $\mathrm{Hb}$ or its breakdown products, triggering harmful oxidative and inflammatory events. ${ }^{1-3}$ Commonly studied experimental models of $\mathrm{ICH}$ and subarachnoid hemorrhage include cerebral vessel perforation, collagenase digestion, or the direct injection of $\mathrm{Hb}$ or blood into brain compartments outside the confines of the blood-brain barrier (BBB). ${ }^{3-7}$ Given that an intact BBB blocks CNS entry of extracellular $\mathrm{Hb}$, considerably less attention has focused on studying the potential CNS effects of plasma cell-free $\mathrm{Hb}$. For example, relatively little is known about how systemic exposure to $\mathrm{Hb}$ may affect the function and integrity of the BBB. This may be particularly important given the well-documented susceptibility of vascular endothelium to $\mathrm{Hb}$ or heme-mediated oxidative injury and the reported vasculopathies associated with chronic or intermittent hemolysis. ${ }^{8-12}$

The development of oxygen-carrying solutions that use cell-free $\mathrm{Hb}$ as a basis for chemical modification has been linked to serious adverse events, including stroke and myocardial infarction, in late-phase clinical trials. ${ }^{13}$ The mechanisms underlying these events are not fully understood but could be related, in part, to the uncon-

Supported by a Critical Path Initiative award from CBER/FDA (F.D. and P.W.B.).

Accepted for publication December 7, 2010.

The findings and conclusions in this article have not been formally disseminated by the Food and Drug Administration and should not be construed to represent any agency determination or policy.

Supplemental material for this article can be found at http:// ajp.amjpathol.org or at doi:10.1016/j.ajpath.2010.12.006.

Address reprint requests to Felice D'Agnillo, Ph.D., Center for Biologics Evaluation and Research, Food and Drug Administration, 29 Lincoln Dr., Bldg. 29, Rm. 129, Bethesda, MD, 20892. E-mail: felice.dagnillo@ fda.hhs.gov. 
trolled pro-oxidative activity of cell-free $\mathrm{Hb}$ or heme., Similarly, neurologic complications (eg, stroke) are commonly observed in disease states associated with chronic or intermittent intravascular hemolysis, including genetic and drug-induced hemolytic anemias, microbial infections, and trauma. ${ }^{11,12,14-18}$ However, the mechanisms are multifaceted and not fully defined. ${ }^{12,17,18}$

Extracellular $\mathrm{Hb}$ can oxidize to methemoglobin (ferric, $\left.\mathrm{Fe}^{3+}\right)$, ferryl heme intermediate $\left(\mathrm{Fe}^{4+}\right)$, hemichromes, and free heme or iron, which can initiate or propagate oxidative damage to lipids, nucleic acids, and proteins. ${ }^{8,9}$ Cell-free $\mathrm{Hb}$ is also an effective scavenger of nitric oxide, a key mediator of vascular homeostasis. ${ }^{11,14}$ Heme catabolism and iron sequestration systems play a key role in mediating tissue responses to cell-free $\mathrm{Hb}$. 8,9,19 Heme oxygenase $(\mathrm{HO})$, the rate-limiting enzyme of heme catabolism, exists as two main isoforms, inducible $\mathrm{HO}-1$ and constitutive $\mathrm{HO}-2$ that catalyze the degradation of heme to biliverdin, free iron, and carbon monoxide. ${ }^{20} \mathrm{HO}-1$ is up-regulated by heme, heavy metals, lipopolysaccharide, and several other stimuli. In the brain, $\mathrm{HO}-1$ induction has been reported in $\mathrm{ICH}$, subarachnoid hemorrhage, and other neurodegenerative conditions. ${ }^{7,21-26} \mathrm{HO}-1$ up-regulation is viewed as an adaptive response that confers protection through antiinflammatory, anti-apoptotic, and antioxidant mechanisms. ${ }^{20,24,25}$ However, under settings of excess heme exposure, $\mathrm{HO}-1$ over-activation may lead to iron or other by-product toxicities and can serve as a marker of oxidative stress. ${ }^{7,23,26,27}$

The BBB is composed of endothelial cells, basal lamina, astrocytic end-foot processes, pericytes, perivascular macrophages, and neurons. ${ }^{28,29}$ Tight junctions (TJs) are specialized interendothelial structural complexes that restrict paracellular permeability. TJs are composed of transmembrane proteins, including occludin, claudins (primarily claudin-3 and -5 ), junctional adhesion molecules (JAMs), and cytoplasmic zonula occludens (ZO) family members (ZO-1, -2, -3). ZO proteins are accessory proteins that bind the other proteins to the actin cytoskeleton. ${ }^{28,29}$ Astrocytes, pericytes, and perivascular macrophages play a central role in BBB regulation. Activated astrocytes express increased levels of glial fibrillary acidic protein (GFAP), which serves as a reliable marker of BBB dysfunction or injury. ${ }^{30,31}$ Pericytes are enveloped within the basal lamina and provide direct structural support to the cerebral endothelium as well as metabolic support through the release of growth factors. ${ }^{32,33}$ Perivascular macrophages are located abluminally and serve as phagocytic regulators of the perivascular environment. ${ }^{32}$

In this study, we examined the effects of a polymerized cell-free $\mathrm{Hb}$ on BBB integrity and oxidative stress in a guinea pig exchange transfusion model. This model was selected on the basis of previous studies that identified the guinea pig as a potentially useful species for studying the oxidative toxicity of cell-free $\mathrm{Hb} .^{9,19,34}$ The guinea pig, similar to humans, lacks the ability to produce ascorbate, which is a powerful reductant that minimizes the oxidation of cell-free $\mathrm{Hb}$ in the circulation. ${ }^{9,34}$ Here, we provide evidence that systemic $\mathrm{Hb}$ exposure triggers BBB disruption and oxidative stress in this model.

\section{Materials and Methods}

\section{Materials}

Polymerized bovine hemoglobin (Oxyglobin; HbG), a product approved for veterinary use, was a kind gift from Biopure Corporation (Cambridge, MA). This solution consists of a heterogeneous mixture of glutaraldehyde-polymerized bovine hemoglobin at a concentration of 13 $\mathrm{g} / \mathrm{dl}$ in modified Lactated Ringer's solution. The solution contains unstabilized tetramers $(<5 \%)$, stabilized $64-\mathrm{kDa}$ tetramers $(\sim 35 \%)$, 65- to $130-\mathrm{kDa}$ oligomers $(\sim 50 \%)$, and $500-k$ Da polymers $(<10 \%)$. Detailed physicochemical characterization has been previously reported. ${ }^{35}$ The initial content of $\mathrm{HbG}$ in the ferric form was $5.7 \%$. All other chemicals were obtained from Sigma (St. Louis, MO) unless indicated otherwise.

\section{Animal Experiments}

Male Hartley guinea pigs (Charles Rivers Laboratories, Wilmington, MA) were acclimated for 1 week on arrival to the Food and Drug Administration/Center for Biologics Evaluation and Research animal care facility. All animals weighed 350 to $400 \mathrm{~g}$ before surgery. Animal protocols were approved by the Food and Drug Administration/ Center for Biologics Evaluation and Research Institutional Animal Care and Use Committee, with all experimental procedures performed in adherence to the National Institutes of Health guidelines on the use of experimental animals. For surgery, guinea pigs were anesthetized i.p. with a ketamine $\mathrm{HCl}(100 \mathrm{mg} / \mathrm{kg})$ and xylazine $\mathrm{HCl}(5$ $\mathrm{mg} / \mathrm{kg}$ ) cocktail (Phoenix Scientific Inc., St. Joseph, MO). All procedures were performed under aseptic conditions. A midline incision was made around the neck region, allowing for blunt dissection and exposure of the right common carotid artery and the left external jugular vein. Saline-filled catheters containing $50 \mathrm{IU}$ heparin/ml prepared from sterile PE50 tubing (Clay Adams of BectonDickenson, Sparks, MD) were placed in each vessel and tunneled under the skin to the back of the neck. Animals were treated for pain immediately after surgery with 5 $\mathrm{mg} / \mathrm{kg}$ ketoprofen, given subcutaneously, and topical application of lidocaine $0.1 \%$. All animals were allowed 24 hours of recovery before experimentation. Animals then underwent a $50 \%$ exchange transfusion with $\mathrm{HbG}$ by connecting the arterial and venous catheters to separate syringe pumps (Model 11; Harvard Apparatus, Holliston, MA) set on withdrawal $(1 \mathrm{ml} / \mathrm{min})$ and infuse $(1 \mathrm{ml} / \mathrm{min})$, respectively. Fifty percent transfusion volume in the guinea pig was calculated as $50 \%$ transfusion $(\mathrm{ml})=[0.06(\mathrm{ml} / \mathrm{g}) \times$ body weight $(\mathrm{g})+0.77] / 2$. The mean doses of $\mathrm{HbG}$ administered and the resulting end-transfusion maximum plasma $\mathrm{HbG}$ concentrations were $3272 \pm 106 \mathrm{mg} / \mathrm{kg}$ and $4.0 \pm$ $0.2 \mathrm{~g} / \mathrm{dl}$, respectively. ${ }^{34}$ The half-life of $\mathrm{HbG}$ was calculated as 15.7 hours. ${ }^{34}$ Two additional control groups included animals subjected to a $50 \%$ exchange transfusion with $5 \%$ human albumin $(n=9$; Baxter Healthcare Corp., 
Round Lake, IL) or shed guinea pig whole blood $(n=9)$. At the end of the desired time period, animals were humanely euthanized and perfused via the arterial catheter with $60 \mathrm{ml}$ of cold saline. Brains were excised, and right and left hemispheres were separated. One-half was stored in $10 \%$ formalin, and the other half was frozen at $-80^{\circ} \mathrm{C}$. Alternatively, animals were perfused with cold saline followed by $10 \%$ formalin before brain collection.

\section{Antibodies}

Mouse monoclonal and rabbit polyclonal antibodies to ZO-1 (catalog no. 33-9100, 61-7300) and mouse monoclonal antibodies to claudin-5 (catalog no. 35-2500) and occludin (catalog no. 33-1500) were purchased from Invitrogen (Carlsbad, CA). Mouse anti-GFAP (clone SMI22) was purchased from Calbiochem (San Diego, CA). Rabbit polyclonal anti-HO-1 (catalog no. SPA-894) and anti-HO-2 (catalog no. OSA-200) were purchased from Assay Designs (Ann Arbor, MI). Mouse monoclonal antiCD163 (clone EDHu-1) was obtained from AbD Serotec (Raleigh, NC). Mouse monoclonal antibodies to 8-hydroxydeoxyguanosine (8-OHdG; N45.1) and 4-hydroxynonenal protein adducts (HNEJ-2) were purchased from Oxis International (Foster City, CA). Rabbit polyclonal anti-cleaved caspase-3 antibody (catalog no. 9661) was purchased from Cell Signaling Technologies (Danvers, MA). Donkey anti-guinea pig IgG-horseradish peroxidase was purchased from Millipore (Billerica, MA). Rabbit polyclonal anti-actin was obtained from Santa Cruz Biotechnologies (Santa Cruz, CA).

\section{Preparation of Whole Brain Lysates}

Frozen brains were sectioned coronally, and samples (250 mg) consisting primarily of frontal cortex were dounce-homogenized in the presence of ice-cold modified radioimmunoprecipitation assay buffer $(50 \mathrm{mmol} / \mathrm{L}$ Tris, $150 \mathrm{mmol} / \mathrm{L} \mathrm{NaCl}, 1 \%$ IgePal-630, 0.5\% deoxycholate, $1 \mathrm{mmol} / \mathrm{L}$ EDTA) containing protease inhibitors (Cocktail Set III; Calbiochem). Lysates were centrifuged at $10,000 \mathrm{rpm}$ at $4^{\circ} \mathrm{C}$ for 30 minutes, and supernatants were collected, divided into aliquots, and stored at $-80^{\circ} \mathrm{C}$. Protein concentrations were measured with the use of the BCA protein assay (Thermo Scientific, Rockford, IL).

\section{IgG Extravasation}

BBB integrity was assessed with the use of a one-step immunoblot assay for guinea pig IgG. ${ }^{36}$ Briefly, brain lysates $(10 \mu \mathrm{g}$ ) were resolved on $4 \%$ to $12 \%$ Bis-Tris gels, transferred to polyvinylidene fluoride membranes, and blocked for 1 hour in Tris-buffered saline containing 0.1\% Tween 20 with 5\% nonfat dry milk. Membranes were incubated with donkey anti-guinea pig IgG-horseradish peroxidase-conjugated antibody (dilution 1:5000) in 1\% nonfat dry milk for 2 hours at room temperature. Signal was developed with the ECL Plus kit (GE Healthcare, Piscataway, $\mathrm{NJ}$ ) and detected on HyperECL film. Blots were stripped and reprobed for actin to control for protein loading. The protein band representing the light chain of IgG ( $\sim 25$ $\mathrm{kDa}$ ) was analyzed by densitometry with the use of the Image J software (National Institutes of Health, Bethesda, $\mathrm{MD}$ ) and normalized to total actin levels. Diluted guinea pig plasma (1:400) was analyzed as a positive control sample.

\section{Western Blot Analyses}

Brain lysates were resolved on $4 \%$ to $12 \%$ Bis-Tris or $3 \%$ to $8 \%$ Tris-Acetate (for ZO-1) gels, transferred to polyvinylidene fluoride membranes, and blocked for 1 hour in Tris-buffered saline containing $0.1 \%$ Tween 20 with 5\% nonfat dry milk. Membranes were incubated overnight at $4^{\circ} \mathrm{C}$ with antibodies to ZO-1 (1:1000), occludin (1:500), claudin-5 (1:1000), GFAP (1:5000), HO-1 (1:2000), HO-2 (1:5000), and cleaved caspase-3 (1:2000) in Tris-buffered saline containing $0.1 \%$ Tween 20 with $1 \%$ nonfat dry milk or $1 \%$ bovine serum albumin (for occludin), washed, and then incubated with a relevant horseradish peroxidase-conjugated secondary antibody for 1 hour. Signal was developed with the use of the ECL Plus kit and detected on HyperECL film. Membranes were stripped and reprobed for actin. Densitometry analysis was performed with the use of the ImageJ software with normalization to actin.

\section{Heme Oxygenase Activity}

Brain microsomes were prepared by ultracentrifugation as previously described. ${ }^{37}$ Microsomal membranes (0.5 to $1 \mathrm{mg} / \mathrm{ml}$ ) were added to reaction mixtures containing glucose 6-phosphate (2 mmol/L), glucose-6-phosphate dehydrogenase $(1.6 \mathrm{U} / \mathrm{ml})$, hemin $(15 \mu \mathrm{mol} / \mathrm{L}), \mathrm{NADPH}$ p450 reductase $(0.1 \mathrm{U} / \mathrm{ml}), 0.5 \mathrm{mg} / \mathrm{ml}$ of rat liver cytosol prepared from a $105,000 \times g$ supernatant fraction as a source of biliverdin reductase, in potassium phosphate buffer (100 mmol/L, $\mathrm{pH}$ 7.4) containing $2 \mathrm{mmol} / \mathrm{L} \mathrm{MgCl}_{2}$. After adding NADP $(0.8 \mathrm{mmol} / \mathrm{L})$ to the experimental tube and assay buffer to the reference tube, the mixtures were incubated in a shaking water bath for 30 minutes at $37^{\circ} \mathrm{C}$ in the dark. The tubes were then placed on ice for 2 minutes and subsequently analyzed on a dual-beam scanning spectrophotometer (Perkin Elmer Lambda 18, Shelton, CT). Bilirubin was calculated by the difference in absorbance between 464 and $530 \mathrm{~nm}\left(40 \mathrm{mmol} / \mathrm{L} \mathrm{cm}^{-1}\right)$. Heme oxygenase activity was expressed as nanomoles of bilirubin formed per hour per milligram of cell protein. Protein content was determined with the use of the BioRad assay (Bio-Rad, Hercules, CA).

\section{Immunohistochemistry}

Brains were fixed in 10\% formalin and embedded in paraffin, and $5-\mu \mathrm{m}$ sections were prepared. Sections were de-waxed in xylene and rehydrated in graded ethanol and deionized water. Antigen retrieval was performed by heat treatment in a microwave oven for 15 minutes in $10 \mathrm{mmol} / \mathrm{L}$ sodium citrate buffer $(\mathrm{pH} \mathrm{6.0)}$, cooled for 30 minutes at room temperature, and rinsed with deionized water and PBS containing $0.05 \%$ 
Tween-20 (PBS-T). Sections were incubated with 3\% $\mathrm{H}_{2} \mathrm{O}_{2}$ in PBS-T for 15 minutes at room temperature. For 4-HNE and 8-OHdG, this peroxidase inhibition step was carried out after the primary antibody incubation to avoid detecting any potential oxidative damage caused by $\mathrm{H}_{2} \mathrm{O}_{2}$. Sections were blocked with PBS-T containing $10 \%$ normal horse or goat serum and $0.25 \%$ Triton- $X$ for 1 hour at room temperature followed by incubation with primary antibodies to GFAP (1:500), HO-1 (1:400), 4-HNE (1 $\mu \mathrm{g} /$ $\mathrm{ml})$, and $8-\mathrm{OHdG}(1 \mu \mathrm{g} / \mathrm{ml})$ overnight at $4^{\circ} \mathrm{C}$. Signal was developed by peroxidase-conjugated avidin-biotin complexes (Vectastain Elite ABC; Vector Laboratories, Burlingame, CA) and diaminobenzidine (SigmaFast DAB; Sigma). Slides were washed, counterstained with hematoxylin unless otherwise indicated, washed, and dehydrated in graded ethanol and xylene. For negative controls, sections were incubated without the primary antibody.

Slides were imaged with the use of an Olympus IX71 inverted microscope equipped with an Olympus DP70 digital camera (Olympus America, Melville, NY). Images were obtained from the cerebral cortex or midbrain regions unless otherwise noted. Standardized microscope and software settings were applied during image capture and processing. Semiquantitative analysis of $8-\mathrm{OHdG}$ staining was performed with the use of the Photoshop software (Adobe Systems, Mountain View, CA). A total of five random cortical fields were imaged at $\times 200$ magnification and evaluated with the optical density function. Staining intensity was reported as mean of arbitrary units $(A U) \pm$ SEM. Sections incubated with anti-8-OHdG antibody in the presence of $500 \mu \mathrm{mol} / \mathrm{L} 8-\mathrm{OHdG}$ as an absorption control showed minimal reactivity.

\section{Immunofluorescence}

Paraffin-embedded slides were dewaxed and rehydrated. Slides were heat treated in a microwave oven for 15 minutes in $10 \mathrm{mmol} / \mathrm{L}$ Tris, $1 \mathrm{mmol} / \mathrm{L}$ EDTA buffer, $\mathrm{pH}$ 9.0 (claudin-5) or $10 \mathrm{mmol} / \mathrm{L}$ sodium citrate buffer, $\mathrm{pH} 6.0$ (HO-1, CD163, 4-HNE, 8-OHdG); cooled for 30 minutes at room temperature; and rinsed with deionized water and PBS-T. For ZO-1, sections were incubated with pep$\sin$ (Invitrogen) for 10 minutes at $37^{\circ} \mathrm{C}$ and rinsed with PBS-T. Sections were then blocked in PBS-T with 5\% goat serum and $0.25 \%$ Triton-X for 1 hour at room temperature followed by overnight incubation with mouse monoclonal anti-claudin-5 (1:100), rabbit polyclonal anti-ZO-1 (1:50), rabbit polyclonal anti-HO-1 (1:400), mouse anti-CD163 (1:100), mouse anti-8-OHdG (1 $\mu \mathrm{g} /$ $\mathrm{ml})$, or mouse anti-4-HNE $(1 \mu \mathrm{g} / \mathrm{ml})$ at $4^{\circ} \mathrm{C}$. Sections were rinsed and incubated with relevant Alexa Fluor 488-and Alexa Fluor 555-conjugated secondary antibodies for 1 hour at room temperature. Nuclei were counterstained with Hoechst 33342. For double-labeling experiments, primary antibodies were mixed together and incubated overnight at $4^{\circ} \mathrm{C}$. Images were acquired with a Zeiss LSM 710 confocal laser scanning microscope (Carl Zeiss Microlmaging Inc., Jena, Germany). Alexa Fluor 488, Alexa Fluor 555, and Hoechst 33342 were excited with 488-, 543-, and 750-nm wavelengths, respectively. Images of $1024 \times 1024$ pixels were acquired with a $100 \times$ oil ob- jective. Image analysis was performed with the Zeiss Zen software. Alternatively, images were processed with an Olympus IX71 inverted microscope equipped with an Olympus DP70 digital camera.

\section{Brain Iron Measurement}

Brain cortical tissue $\left(50 \mathrm{mg}\right.$ ) was homogenized in $\mathrm{dd}_{2} \mathrm{O}$ at $1: 10 \mathrm{w} / \mathrm{v}$. Homogenates were mixed with $500 \mu \mathrm{l}$ of an acid mixture containing $1 \mathrm{mmol} / \mathrm{L} \mathrm{HCl}$ and $10 \%$ trichloro acetic acid, and incubated at $50^{\circ} \mathrm{C}$ for 1 hour with intermittent shaking. ${ }^{38}$ The samples were then centrifuged at $15,000 \times g$ for 15 minutes at room temperature. The clear supernatant $(90 \mu \mathrm{l})$ was mixed with $30 \mu \mathrm{l}$ of $20 \mathrm{mg} / \mathrm{ml}$ ascorbic acid followed by $20 \mu \mathrm{l}$ ferrozine $(0.85 \% \mathrm{w} / \mathrm{v}$ in hydroxylamine hydrochloride). The samples were allowed to completely develop for 30 minutes. Absorbance was measured at $560 \mathrm{~nm}$ with the use of the Synergy 4 Hybrid Multi-Mode microplate reader (Biotek, Vinooski, VT). A standard curve was generated with the use of an iron standard (500 $\mu \mathrm{g} / \mathrm{dl})$.

\section{Non-Heme Iron Histochemistry with $D A B$ Intensification}

Non-heme ferric iron deposition was detected with the use of Perls method with DAB intensification. ${ }^{39}$ Sections were incubated with Perls iron reagent containing 5\% potassium ferrocyanide and $2 \%$ hydrochloric acid for 45 minutes at room temperature and rinsed in deionized water. Sections were then incubated with $0.3 \%$ hydrogen peroxide and $0.01 \mathrm{~mol} / \mathrm{L}$ sodium azide in methanol for 30 minutes at room temperature. All sections were then rinsed in $0.1 \mathrm{~mol} / \mathrm{L}$ phosphate buffer, $\mathrm{pH} 7.4$, incubated with $\mathrm{DAB}$ for 5 minutes, washed in deionized water, and lightly counterstained with Gill's II hematoxylin. Images of the cerebral cortex were obtained with the use of the Olympus IX71 inverted microscope.

\section{Data Presentation and Statistics}

Data are represented as means \pm SEMs for replicate experiments. A value of $P<0.05$ was considered statistically significant. Statistical significance for all comparisons was determined by analysis of variance using the JMP Discovery Statistical Software v5.1 (Version 3.2; SAS Institute, Cary, NC).

\section{Results}

\section{Altered TJ Protein Expression and Organization after HbG Transfusion}

To determine the effect of $\mathrm{HbG}$ on cerebral TJs, we examined the expression of ZO-1, occludin, and claudin- 5 by Western blot. In HbG-transfused animals, ZO-1 expression was significantly reduced after 4,12 , and 24 hours compared with nontreated sham controls (Figure 1A). At 72 hours, no significant difference in ZO-1 was detected between both groups. For occlu- 
A
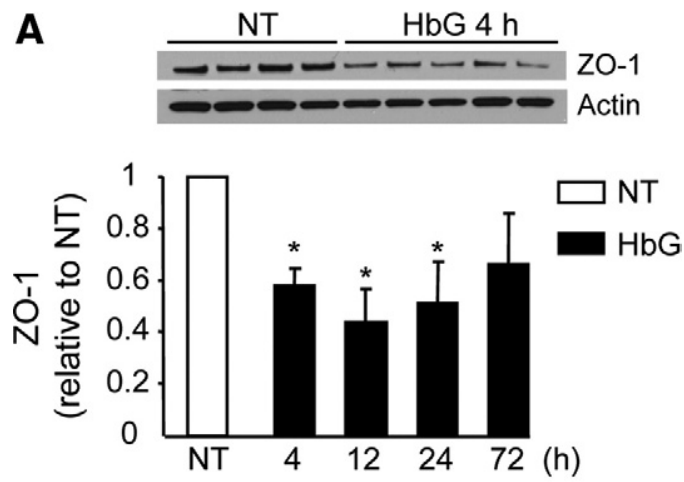

B
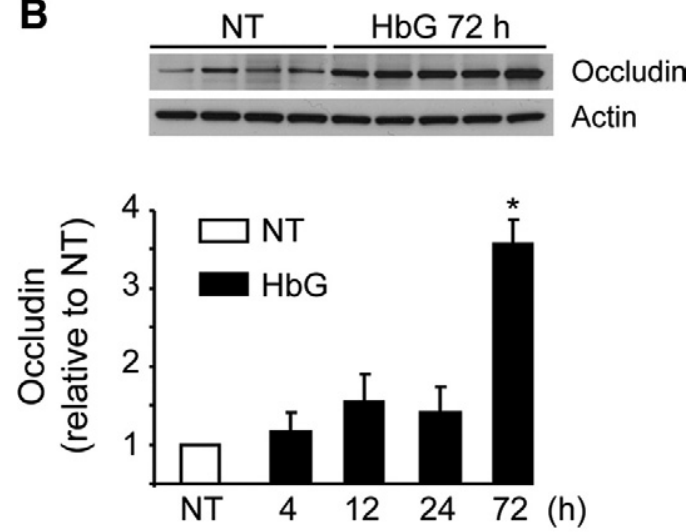

C
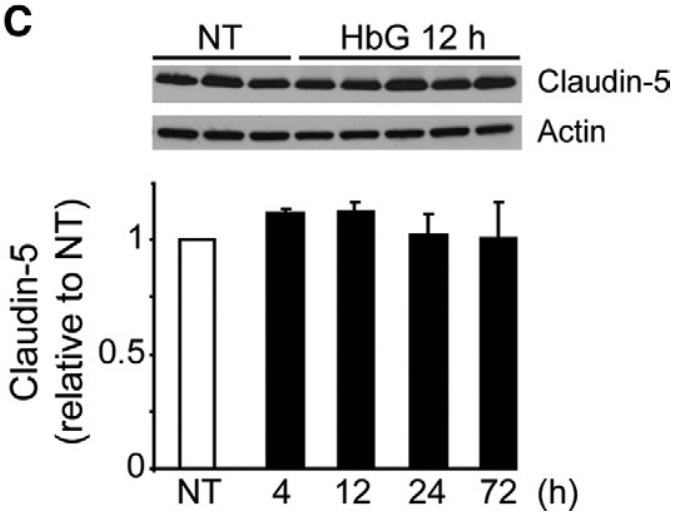

Figure 1. Tight junction protein expression after $\mathrm{HbG}$ transfusion. Brains were harvested from sham-operated controls (NT) and HbG-transfused animals after the indicated times. Lysates were prepared and analyzed for ZO(A), occludin (B), and claudin-5 (C) by Western blot as described in Materials and Methods. Representative immunoblots for ZO-1 (4 hours), occludin ( 72 hours), and claudin-5 (12 hours) are shown with each lane representing a separate animal. Bands for ZO- 1 , occludin, and claudin -5 migrated at approximately 200,65 , and $22 \mathrm{kDa}$, respectively. Densitometry values for protein expression as a ratio to actin were normalized to NT and presented as the means \pm SEMs. ${ }^{*} P<0.05$ vs NT ( 4 to 5 animals per time point).

din, no change in expression was observed at 4, 12, or 24 hours. However, a notable threefold increase in occludin was measured after 72 hours (Figure 1B). Total expression of claudin- 5 was not altered at any time point after $\mathrm{HbG}$ transfusion (Figure 1C). In shed blood or albumin-transfused animals, there was no significant change in the expression of ZO-1, occludin, and claudin-5 compared with nontreated sham controls at 12 and 72 hours (see Supplemental Figure S1 at http://ajp.amjpathol.org).
To further examine the distribution of TJ proteins, ZO-1 and claudin- 5 were analyzed by confocal microscopy. Blood vessels from nontreated sham controls showed intense and continuous reactivity for ZO-1 in large and medium- to small-sized vessels (Figure 2, A-C). Conversely, in HbG-transfused animals, ZO-1 immunoreactivity was comparatively lower and appeared more punctuate and diffuse (Figure 2, D-F). Claudin-5 immunoreactivity in sham controls showed intense and continuous interendothelial borders (Figure 2, G-I). In large vessels, both groups generally showed a similar claudin- 5 staining pattern. However, in HbG-transfused animals, a high number of medium- to small-sized vessels exhibited a discontinuous and more diffuse claudin- 5 staining pattern compared with similar-sized vessels in sham controls (Figure 2, J-L).

\section{Astrocyte Activation and IgG Extravasation after HbG Transfusion}

Up-regulation of GFAP in astrocytes is considered a reliable marker of BBB disruption in models of CNS disease and toxicity. ${ }^{30,31}$ GFAP expression was analyzed over the course of 72 hours after $\mathrm{HbG}$ transfusion by Western blot. GFAP was detectable at 4, 12, and 24 hours but showed high variability, whereas a significant expression was observed at 72 hours $(P<0.01)$ (Figure 3A). Consistent with these data, increased GFAP immunoreactivity was observed in astrocyte processes surrounding many mediumto small-sized blood vessels in the brain parenchyma (Figure 3B). The glial limitans of the brain surface also showed enhanced GFAP immunoreactivity compared with sham control animals. GFAP was not up-regulated after exchange transfusion with shed blood or albumin (data not shown).

As a measure of BBB permeability, we analyzed plasma IgG extravasation via Western blot. In HbG-transfused animals, there were minor changes in IgG extravasation at 4 hours $(P=0.17), 12$ hours $(P=0.26)$, and 24 hours $(P=0.07)$, but a significant increase at 72 hours $(P<0.001)$ compared with sham controls (Figure 3C). These data suggest that, within the first 24 hours, there were no major changes in permeability to large-sized molecules (IgG; mol. wt., 150 kDa), but a leakier barrier develops by 72 hours. In contrast, there was no significant increase in IgG extravasation in the shed blood or albumin groups after 72 hours (see Supplemental Figure S1 at http://ajp.amjpathol.org). In separate analyses, we used a histochemical stain for $\mathrm{Hb}^{40}$ to monitor for possible $\mathrm{HbG}$ extravasation during the first 24 hours when significant quantities of circulating $\mathrm{HbG}$ were still present. Consistent with the IgG observations, we did not observe widespread $\mathrm{HbG}$ extravasation into the brain parenchyma during the first 24 hours.

\section{Heme Oxygenase Induction after $\mathrm{HbG}$ Transfusion}

As an index of $\mathrm{HbG}$ or heme exposure, we analyzed total $\mathrm{HO}$ activity and the expression of $\mathrm{HO}-1$ and $\mathrm{HO}-2$. In HbG-transfused animals, we observed progressive in- 

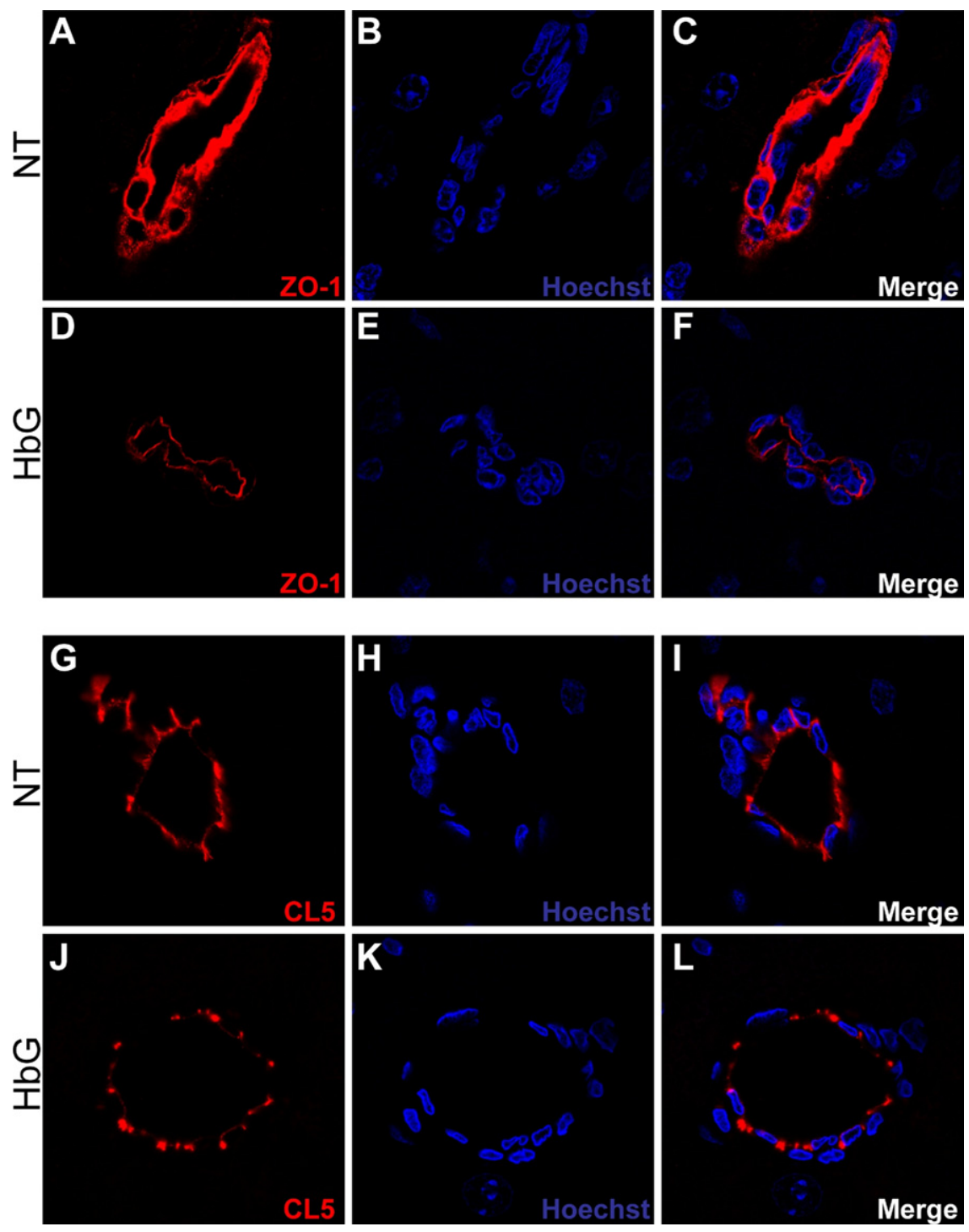

Figure 2. Altered tight junction organization af ter $\mathrm{HbG}$ transfusion. Brain sections from sham controls (A-C, G-I) and HbG 24 hours after transfusion (D-F, J-L) were analyzed for ZO-1 (A-F) or claudin-5 (CL5) (G-L) by laser scanning confocal microscopy as described in Materials and Methods. Reduced ZO-1 intensity is observed after HbG transfusion (D and F) compared with sham controls (A and $\mathbf{C}$ ). Intense and continuous endothelial CL5 immunoreactivity is observed in medium-sized vessels of sham controls ( $\mathbf{G}$ and $\mathbf{I}$ ), whereas CL5 staining was more diffuse in similar-sized vessels of HbG-transfused animals ( $\mathbf{J}$ and $\mathbf{L}$ ). Nuclei were counterstained with Hoechst 33342 (blue). Original magnifications, $\times 1000$. creases in $\mathrm{HO}$ activity that peaked at 12 and 24 hours after transfusion and then declined by 72 hours (Figure 4A). Total $\mathrm{HO}$ activity was unchanged in animals transfused with shed blood ( $P=0.26, n=4)$ or albumin ( $P$ $=0.92, n=3)$ compared with sham controls, suggesting $\mathrm{HO}$ induction was not caused by the surgery or the transfusion procedure itself. Western blot analyses of whole brain lysates showed increased $\mathrm{HO}-1$ expression in HbG-transfused animals, whereas $\mathrm{HO}-2$ expression remained the same compared with sham controls (Figure 4B).

To localize HO-1-expressing cell types, brains sections were analyzed by immunohistochemistry. In $\mathrm{HbG}$-transfused animals, intense $\mathrm{HO}-1$ reactivity was observed in cells forming the walls of small- to medium-sized vessels (capillaries, arterioles) and postcapillary venules (Figure 5, D-F), whereas $\mathrm{HO}-1$ was not detectable in similar-sized vessels in sham controls (Figure 5A). Most of the vessel-associated HO-1-positive cells possessed nuclei positioned abluminally, suggesting they represent pericytes or perivascular macrophages or both. In some cases, highly HO-1reactive cells, which morphologically resembled monocytes/macrophages, accumulated in the lumen of postcapillary venules (Figure 5F). HO-1 immunoreactivity was variably observed in endothelial cells of mediumsized vessels, although this was not nearly as prominent as the perivascular $\mathrm{HO}-1$ staining. Large vessels surrounding the brains of $\mathrm{HbG}$-transfused animals showed extensive perivascular $\mathrm{HO}-1$ reactivity compared with sham controls (see Supplemental Figure S2 at http://ajp.amjpathol.org). In albumin- or shed bloodtransfused controls, $\mathrm{HO}-1$ immunoreactivity was not enhanced in the parenchyma or in large vessels surrounding the brain (Figure $5, \mathrm{~B}$ and $\mathrm{C}$ ). $\mathrm{HO}-1$ staining was detected in scattered neuron populations, but there were no apparent differences in staining intensity between HbG-transfused animals and sham controls.

To further identify the $\mathrm{HO}-1-$ expressing cells, sections were double labeled for $\mathrm{HO}-1$ and $\mathrm{CD} 163$, a marker of pericytes/perivascular macrophages. ${ }^{41,42}$ In sham controls, CD163-positive perivascular cells with minimal 
A
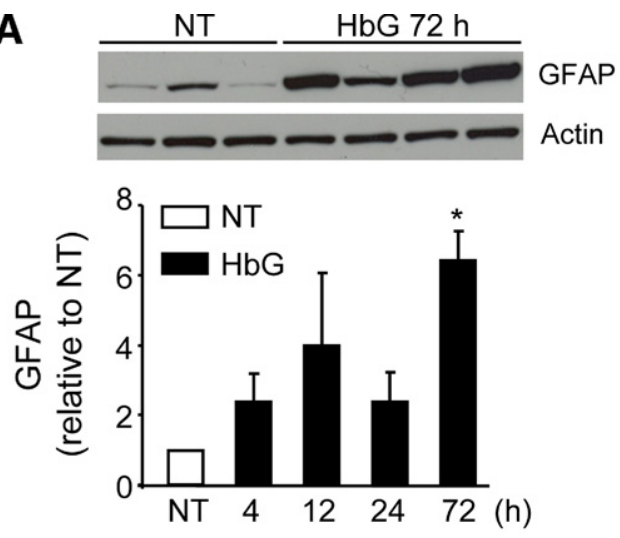

B
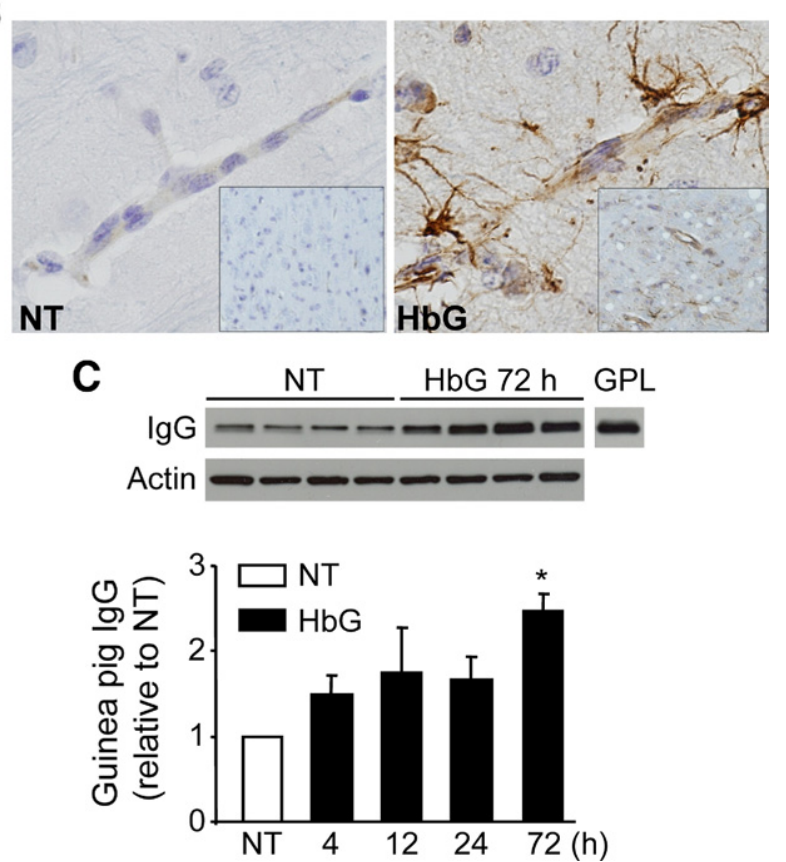

Figure 3. GFAP induction and IgG extravasation in HbG-transfused animals. A: Western blot analysis of GFAP expression in brains harvested from sham controls (NT) and at the indicated times after HbG transfusion. A representative immunoblot for GFAP $(51 \mathrm{kDa})$ at 72 hours is shown. Densitometry values expressed as a ratio to actin were normalized to NT and presented as the means \pm SEMs. ${ }^{*} P<0.01$ vs NT ( 3 to 6 animals per time point). B: GFAP immunohistochemistry was performed as described in Materials and Methods. Minimal GFAP immunoreactivity was observed in brain parenchyma of sham controls (left panel), whereas GFAP was detectable around blood vessels 24 hours after HbG transfusion (right panel). Original magnifications, $\times 600$ (B) and $\times 200$ (insets). C: Western blot analysis of guinea pig IgG. Brain lysates were analyzed with a donkey anti-guinea pig IgG antibody conjugated to horseradish peroxidase. Guinea plasma sample (GPL) served as a positive control. A representative immunoblot for IgG ( 72 hours) is shown. Densitometry was performed on a $25-\mathrm{kDa}$ protein band representing the light chain of IgG. Data from at least four to five animals per group were normalized to NT and presented as the means \pm SEMs. ${ }^{*} P<0.001$ vs NT.

$\mathrm{HO}-1$ reactivity were detectable as flattened and elongated cells around small- to medium-sized blood vessels (Figure 5, G-I). In HbG-transfused animals, HO-1-positive cells that lined the vessel walls and accumulated luminally in venules were also found to be CD163 positive (Figure 5, J-L). Enhanced $\mathrm{HO}-1$ immunoreactivity was not observed in astrocytes or microglia on the basis of staining for GFAP and ionized calcium binding adaptor molecule 1 , respectively (data not shown).
To assess whether enhanced $\mathrm{HO}-1$ expression colocalized with sites of BBB disruption, sections were double labeled for HO-1 and claudin-5 or GFAP. Sham control vessels with minimal $\mathrm{HO}-1$ reactivity showed intact claudin-5 distribution (Figure 6, A-C) and minimal GFAP staining (Figure 6, G-I). In HbG-transfused animals, vessels with intense perivascular or luminal $\mathrm{HO}-1$ reactivity consistently showed irregular or discontinuous claudin-5 immunoreactivity, suggesting a close correlation between vessel exposure to $\mathrm{HbG} /$ heme and sites of $\mathrm{TJ}$ alterations (Figure 6, D-F). Similarly, vessels with enhanced GFAP immunoreactivity frequently showed increased $\mathrm{HO}-1$ expression (Figure 6, J-L).

\section{Non-Heme Iron Deposition after HbG Transfusion}

Because breakdown of $\mathrm{Hb} /$ heme produces iron, we examined brain iron status after $\mathrm{HbG}$ transfusion. To quantitatively assess iron accumulation, brain homogenates were analyzed with the use of a colorimetric ferrozinebased assay. Importantly, this assay was performed with deproteinization conditions that cause minimal release of iron from heme proteins. ${ }^{38}$ In $\mathrm{HbG}$ animals, a significant

A

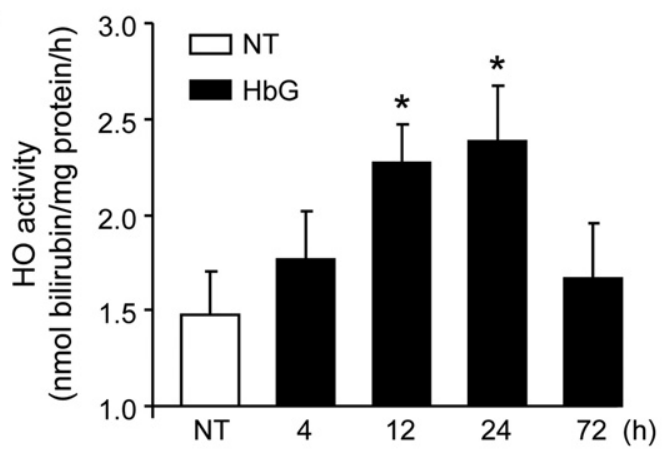

B
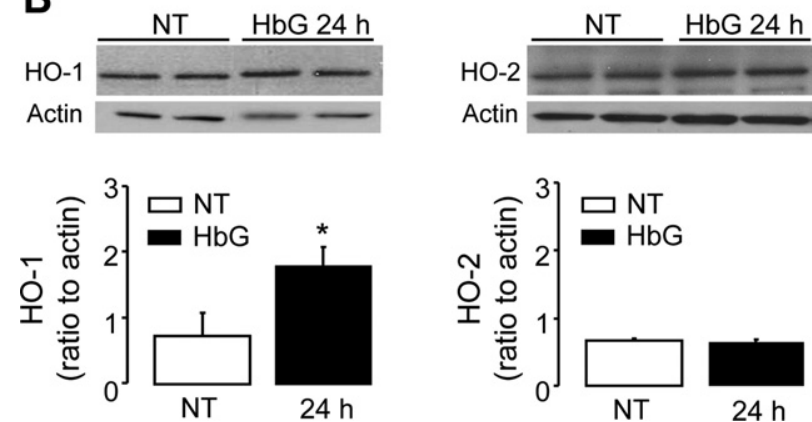

Figure 4. Brain $\mathrm{HO}$ induction in HbG-transfused guinea pigs. A: Brain microsomes were harvested from sham controls and at the indicated times after $\mathrm{HbG}$ transfusion. HO activity was measured by the bilirubin spectrophotometric assay and was reported as nanomole bilirubin formed per hour per milligram of protein. Values are shown as the means \pm SEMs for at least four animals per group for each time point. ${ }^{*} P<0.05$ vs NT. B: Western blot analysis of $\mathrm{HO}-1$ (left panel) and $\mathrm{HO}-2$ (right panel) in brain lysates from sham controls (NT) and 24 hours after HbG transfusion with the use of rabbit polyclonal antibodies as described in Materials and Methods. Representative immunoblots for HO-1 and HO-2 are shown for two different animals per group. Densitometry analysis was performed on at least four animals per group and was expressed relative to actin as the means \pm SEMs. ${ }^{*} P<0.05$ vs NT. 

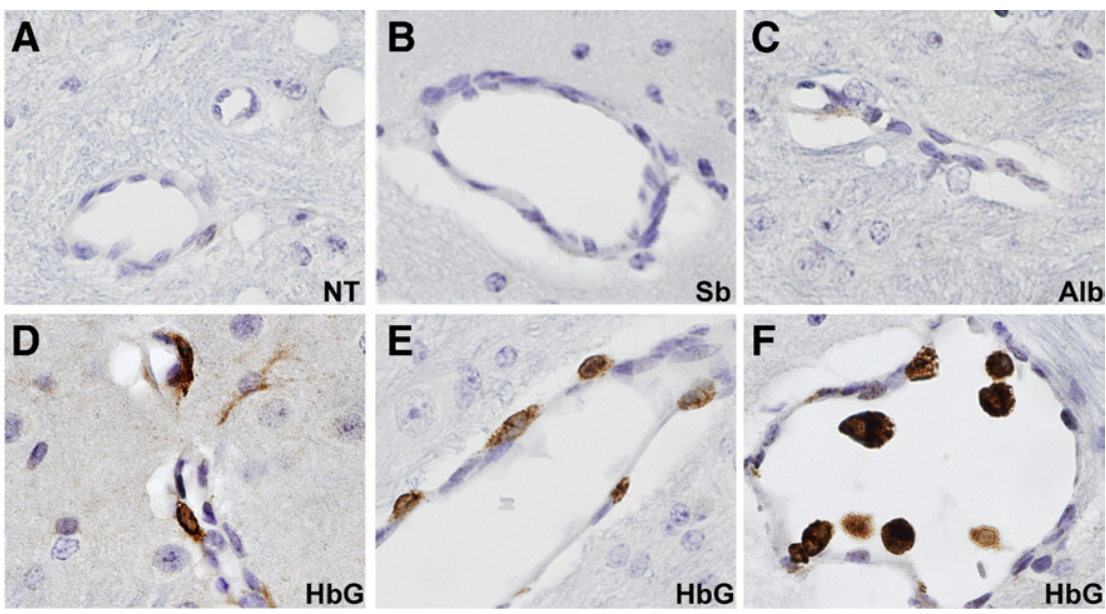

Alb
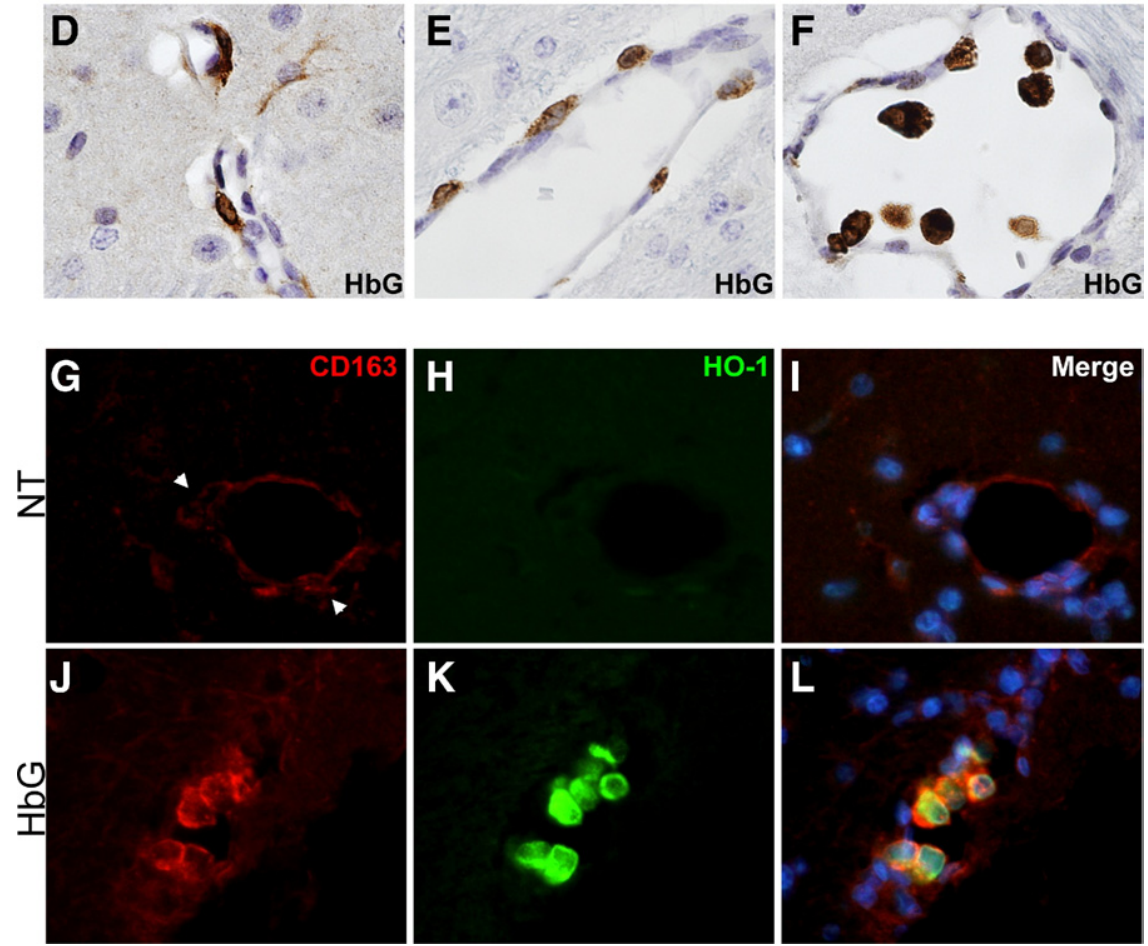

Figure 5. Brain HO-1 expression in HbG-transfused guinea pigs. A-F: For HO-1 immunohistochemistry, brain sections were stained with a rabbit polyclonal HO-1 antibody and detected by Vectastain Elite with DAB as a substrate and counterstained with hematoxylin. A: Sham-operated controls (NT). Minimal HO-1 immunoreactivity in small- and medium-sized vessels in brain parenchyma. B and C: Exchange transfusion with shed blood (Sb) and albumin (Alb) produced minimal blood vessel HO-1 expression after 24 hours. D-F: HbG-transfused guinea pigs after 24 hours. High-intensity HO-1 immunoreactivity in walls of small- and medium-sized vessels (D and $\mathbf{E}$ ) and in cells accumulating within postcapillary venules (F). G-L: Co-localization of HO- 1 and CD163. Brain sections were stained with antibodies to HO-1 and CD163 and detected with the use of relevant secondary antibodies conjugated with Alex Fluor 488 (HO-1, green) and Alex Fluor 555 (CD163, red). Nucle were counterstained with Hoechst 33342 (blue) Sham-operated controls (G-I) and HbG-transfused guinea pigs after 24 hours (J-L). CD163 positive and $\mathrm{HO}-1-$ negative staining observed in a medium-sized vessel of a sham control animal (G, arrowheads). Colocalized HO-1 and CD163 expression in cells trapped in the lumen of a medium-sized vessel of an HbG-transfused animal (L). Brightfield; original magnifications, $\times 600(\mathbf{A}-\mathbf{F})$. Double-label epifluorescence microscopy; original magnification, $\times 600(\mathbf{G}-\mathbf{L})$. increase in iron was measured 24 hours after transfusion compared with sham controls (Figure 7A). Non-heme iron accumulation was also visualized with the use of the Perls DAB intensification method. Iron deposition was not observed in brain sections from sham controls or from shed blood- or albumin-transfused animals (Figure 7, B-D). In HbG-transfused animals, iron deposits were detectable in brain parenchyma at 12 and 24 hours and variably observed at 4 and 72 hours. Iron deposits were primarily detected in neurons, and, in some cases, within cells forming the blood vessels (Figure 7, E and F).

\section{HbG Induces Oxidative Stress and Apoptosis}

To further investigate whether systemic $\mathrm{HbG}$ exposure produces oxidative stress at the level of the BBB, we analyzed 4-HNE-modified adducts, a marker of lipid peroxidation, and 8-OHdG, a marker of oxidative DNA damage. In HbG-transfused animals, the endothelial lining of many medium- to small-sized vessels displayed increased 4-HNE immunoreactivity (Figure 8, A-C). Double-labeling analyses showed strong co-localization of 4-HNE and $\mathrm{HO}-1$ in cellular infiltrates. Consistent with these 4-HNE observations, increased 8-OHdG immunoreactivity was detected in vessels, although endothelial $8-\mathrm{OHdG}$ staining was generally not as intense as that observed for 4-HNE (Figure 8, D-F). Co-localization of 8-OHdG and $\mathrm{HO}-1$ was also prominent among cellular infiltrates. Minimal 4-HNE and 8-OHdG staining was observed in sham controls (see Supplemental Figure S2 at http://ajp.amjpathol.org). Interestingly, in the brain parenchyma, increased 4-HNE and 8-OHdG reactivity was detected in neurons of the cerebral cortex (Figure 8, G and $\mathrm{H})$. This was observed as early as 4 hours but was most prominent at 24 hours. In brain cortical regions, a fourfold increase in the staining intensity of $8-\mathrm{OHdG}$ was observed in the $\mathrm{HbG}$ group compared with sham controls (Figure 8I). Consistent with an increase in oxidative toxicity, HbG-transfused animals showed a 2.5-fold increase in cleaved caspase 3 expression, a specific marker of apoptosis, by Western blot (Figure 8J).

\section{Discussion}

An intact BBB plays a critical role in blocking the entry of potentially neurotoxic cell-free $\mathrm{Hb}$ into the CNS. Yet, there is a paucity of information on how plasma cell-free $\mathrm{Hb}$ may alter the function and integrity of the BBB in vivo. Here, we provide evidence that systemic exposure to a long-circulating polymerized cell-free $\mathrm{Hb}$ solution induces BBB disruption as evidenced by TJ alterations, GFAP up-regulation, and IgG extravasation. This was 

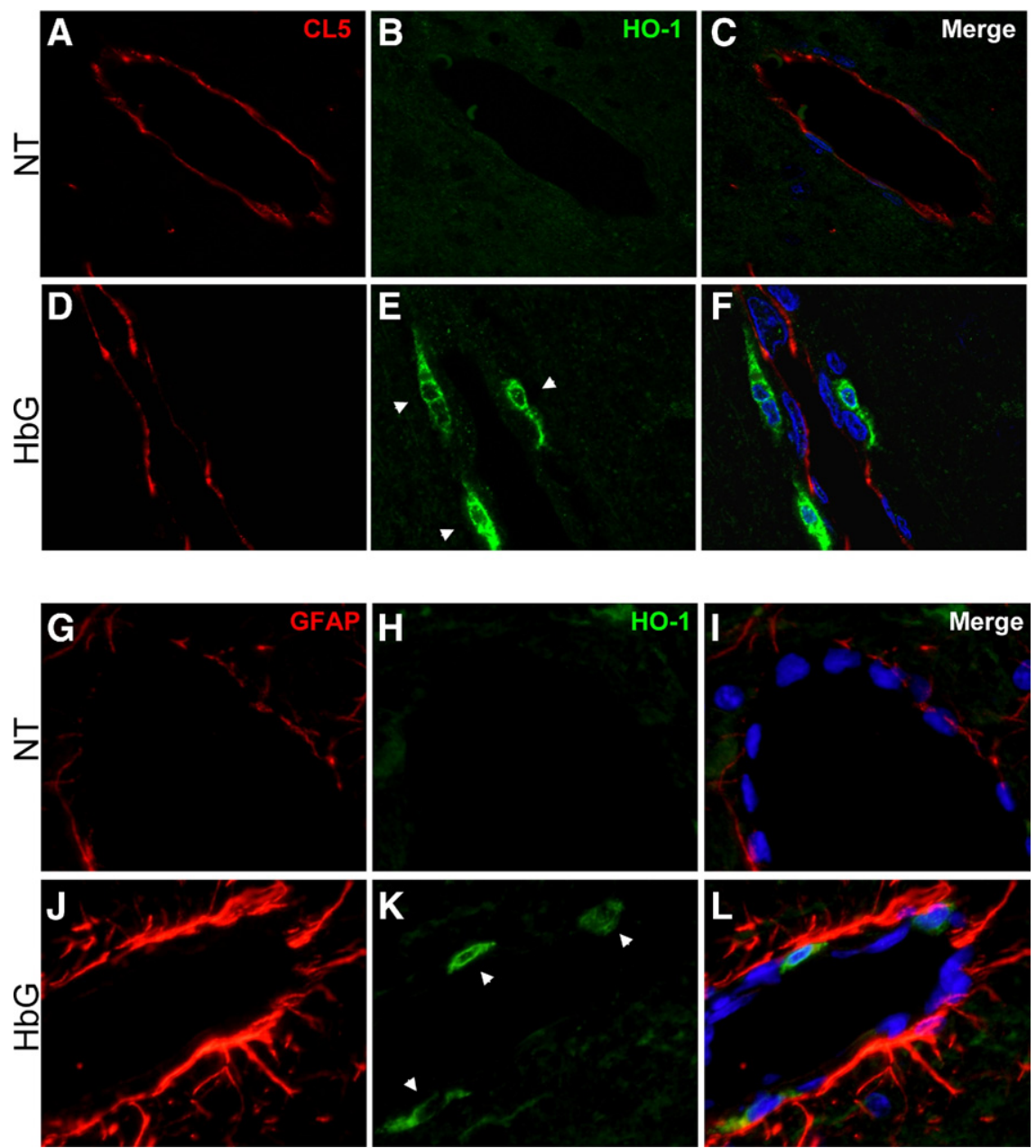

Figure 6. Relationship between $\mathrm{HO}-1$, claudin-5 (CL5), and GFAP expression. Brain sec tions were stained with antibodies to HO- 1 , claudin-5, and GFAP and detected with relevant secondary antibodies conjugated with Alex Fluor 488 (HO-1, green) and Alex Fluor 555 (CL5 and GFAP, red). Nuclei were counterstained with Hoechst 33342 (blue). A-C and G-I: Shamoperated controls. D-F and J-L: HbG-transfused guinea pigs after 24 hours. HO-1-negative staining in vessels showing intact CL5 immunoreactivity (C) and minimal GFAP staining (I). In HbG-transfused animals, HO-1-positive pericytes/perivascular macrophages (arrowheads) lined the walls of vessels with diffuse CL5 staining and enhanced GFAP reactivity. Laser scanning confocal microscopy; original magnification, $\times 700(\mathbf{A}-\mathbf{F})$. Double-label epifluorescence microscopy; original magnification, $\times 400(\mathbf{G}-\mathbf{L})$ accompanied by increased $\mathrm{HO}-1$ expression in pericytes/perivascular macrophages and infiltrating monocyte/macrophages but not in microglia, astrocytes, or neurons. Notably, enhanced $\mathrm{HO}-1$ immunoreactivity was observed in vessels that showed altered claudin- 5 immunostaining and increased GFAP reactivity. Importantly, shed blood- or albumin-transfused control animals did not show tight junction protein alterations or enhanced HO-1 or GFAP in blood vessels. Together, these data suggest that $\mathrm{HbG}$ or its breakdown products or both may preferentially target the endothelial-perivascular cell interface in this setting. This idea is further supported by the prominent oxidative end product accumulation (4HNE-modified protein adducts and $8-\mathrm{OHdG}$ ) along the endothelial lining and immediate perivascular compartments in vessels that co-expressed $\mathrm{HO}-1$.

BBB disruption is typically characterized by changes in the expression, distribution, or phosphorylation of $\mathrm{TJ}$ proteins. $^{28,29} \mathrm{ZO}-1$ is a key cytoplasmic TJ accessory protein that links the transmembrane proteins, occludin and the claudins, to the actin cytoskeleton. In this study, $\mathrm{HbG}$ produced a significant reduction in ZO-1 expression as early as 4 hours after transfusion, reached maximal decline by 12 hours, and partially recovered by 72 hours. Previous studies have shown that oxidative stress can alter ZO-1 expression and the molecular association be- tween ZO-1 and the transmembrane proteins. ${ }^{43-49}$ For example, oxidative stress induced by hypoxia-reoxygenation disrupted ZO-1-occludin interactions in vivo. ${ }^{49} \mathrm{Re}-$ cent findings suggest that oxidative stress induced by intracerebral injection of $\mathrm{Hb}$ triggers matrix metalloproteinase-mediated proteolysis of TJ proteins. ${ }^{5}$ In our study, we detected an accumulation of oxidative end products within the endothelial and perivascular compartments after $\mathrm{HbG}$ transfusion. These data support a possible link between oxidative stress and the reduction in ZO-1 expression, claudin-5 disorganization, and delayed occludin up-regulation.

Unlike ZO-1, the total expression levels of claudin-5 and occludin as determined by Western blot were unchanged after $\mathrm{HbG}$ transfusion. Nevertheless, we did observe altered claudin-5 immunoreactivity in many medium- to small-sized vessels after $\mathrm{HbG}$ transfusion. This could be related to weakened interactions between ZO-1 and claudin-5. Alternatively, others have reported that oxidative stress may modulate the function and localization of $\mathrm{TJ}$ proteins through non-degrading changes in their phosphorylation. ${ }^{47}$ Further investigations on the phosphorylation status of TJ proteins are warranted because this may help shed further light on the molecular mechanisms underlying HbG-mediated TJ disruption. With regard to the occludin data, it is conceivable that the 

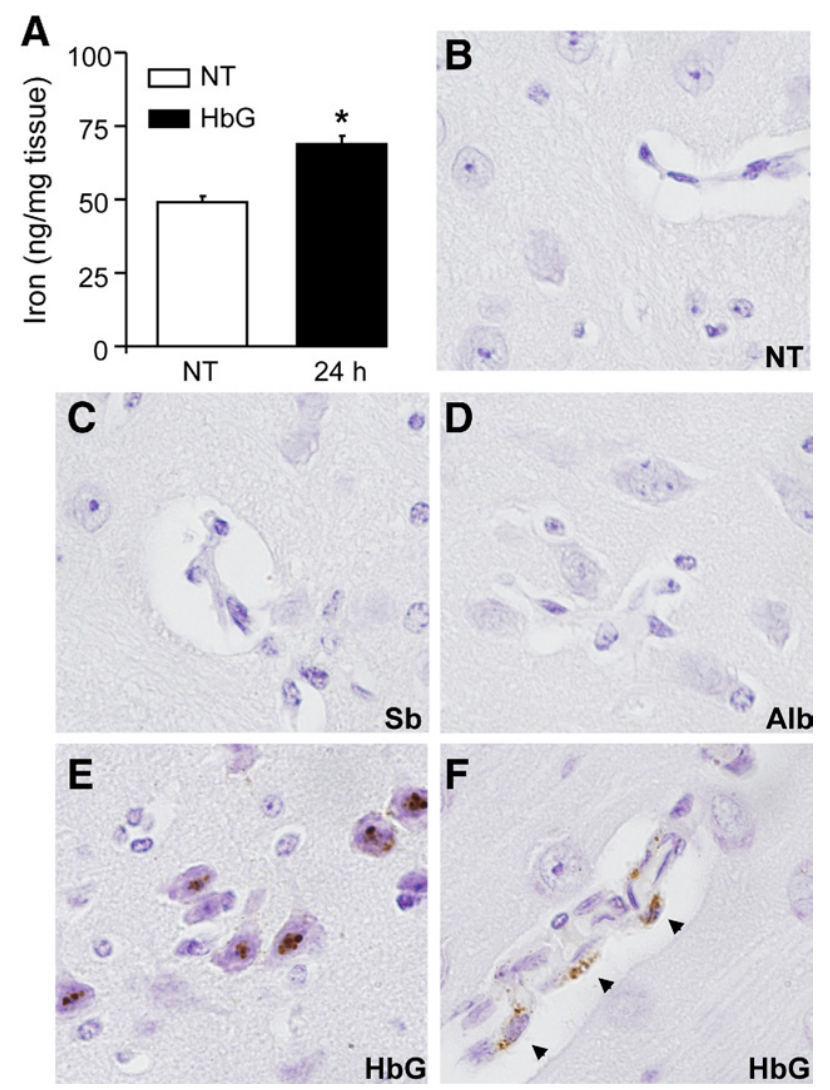

Figure 7. Iron deposition after $\mathrm{HbG}$ transfusion. A: Spectrophotometric determination of iron in brain homogenates prepared from sham controls (NT) and HbG-transfused animals after 24 hours as described in Materials and Methods. Data were obtained from at least four animals per group. Values are expressed as nanogram of iron per milligram of tissue and presented as means \pm SEMs. ${ }^{*} P<0.05$ vs NT. B-F: Perls non-heme iron histochemistry with DAB intensification in sham controls (B) and 24 hours after transfusion with shed blood (C), albumin (D), and HbG (E and $\mathbf{F})$. In HbG animals, non-heme iron deposits were observed primarily in neurons (E) and were variably detected in walls of blood vessels (F, arrowheads) Sections were counterstained with hematoxylin. Original magnification, $\times 600(\mathbf{B}-\mathbf{F})$

observed up-regulation at 72 hours represents an adaptive response designed to reinforce TJ integrity. In support of this view, others have shown that heat shock triggers occludin synthesis as a protective response to heat-induced barrier disruption. ${ }^{50}$ The occludin results are also in line with the astrocytic GFAP induction at 72 hours, which is also known to contribute to barrier repair processes. Others have also shown that occludin alterations during BBB disruption are characterized by the breakdown of functional occludin oligomers in different cellular compartments. ${ }^{49,51}$ Notably, the latter studies used a polyclonal antibody capable of detecting occludin oligomers, whereas we used a monoclonal antibody that mainly recognizes the monomer $60-\mathrm{kDa}$ form of occludin. Therefore, it is possible that the increased expression of occludin monomer at 72 hours could reflect changes in occludin oligomerization that we were unable to detect with the monoclonal antibody.

In this study, $\mathrm{HbG}$ increased total $\mathrm{HO}$ activity levels by 1.6-fold after 24 hours, which compared favorably with the magnitude of $\mathrm{HO}-1$ protein expression by Western blot. Several studies have provided evidence for $\mathrm{HO}$-mediated
CNS protection. ${ }^{20,24,25} \mathrm{HO}$ activity has been implicated in the protection of astrocytes and cerebral endothelial cells but may promote neuronal cytotoxicity. ${ }^{23,52,53}$ Others have shown that $\mathrm{HO}-1$ may exacerbate early brain injury after $\mathrm{ICH}$, and administration of $\mathrm{HO}$ inhibitors re-

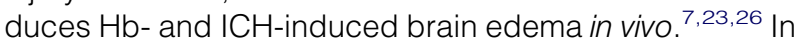
our study, enhanced HO-1 expression served as a useful marker of $\mathrm{HbG} /$ heme exposure and oxidative stress that correlated well with sites of altered TJ organization, enhanced GFAP reactivity, and oxidative end products. The present study was not specifically designed to evaluate whether the $\mathrm{HO}-1$ response was protective or deleterious in this setting. However, recent experiments in our laboratory have shown that pretreatment with zinc protoporphyrin IX, a nonselective $\mathrm{HO}$ inhibitor, can attenuate the increase in brain $\mathrm{HO}$ activity and the reduction in ZO-1 expression after HbG transfusion (see Supplemental Figure S3 at http://ajp.amjpathol.org). These data imply a potential relationship between increased $\mathrm{HO}$ activity and the observed BBB alterations; however, further work will be required to fully understand the role of $\mathrm{HO}$ in this system.

The present study provided evidence for enhanced $\mathrm{HO}-1$ immunoreactivity primarily in pericytes/perivascular macrophages, infiltrating monocytes, and variably in endothelial cells. This is in striking contrast to previous $\mathrm{ICH}$ and subarachnoid hemorrhage studies that have reported up-regulation of $\mathrm{HO}-1$ in microglia, astrocytes, and neurons. ${ }^{22,54,55}$ These differences in the cellular expression may be explained, in part, by the absence of widespread leakage of $\mathrm{HbG}$ into the brain parenchyma.

We previously showed that plasma $\mathrm{HbG}$ undergoes rapid oxidation to methemoglobin, with levels reaching $10 \%$ to $15 \%$ as early as 4 hours after transfusion and up to $30 \%$ by 24 hours. ${ }^{34}$ Heme is known to dissociate more readily from $\mathrm{Hb}$ as ferric $\left(\mathrm{Fe}^{3+}\right.$ ) heme relative to ferrous $\left(\mathrm{Fe}^{2+}\right)$ heme, implying the vasculature could be subjected to greater amounts of free $\left(\mathrm{Fe}^{3+}\right)$ heme. ${ }^{8,56}$ Our previous findings also showed that plasma $\mathrm{HbG}$ oxidation correlated with globin chain destabilization and presumably increased heme release. ${ }^{34}$ As an extension of these earlier findings, we have found that free heme is detectable by mass spectrometry in 24-hour plasma samples from HbG-transfused animals (see Supplemental Figure S4 at http://ajp.amjpathol.org). Several possible mechanisms could account for HbG-mediated oxidative stress and BBB disruption, including: i) The release of heme from oxidized $\mathrm{HbG}$ in amounts sufficient to exceed plasma-scavenging protein capacity. (This may be especially relevant in this exchange transfusion setting, where animals experience a significant loss of plasma $\mathrm{Hb} /$ heme-binding proteins. Highly lipophilic heme could then be taken up by endothelial cells or pericytes/perivascular macrophages and cause oxidative stress.) ii) Small amounts of $\mathrm{HbG}$ may traverse endothelial cells and be scavenged by pericytes/perivascular macrophages that may either be an indicator of, or in some circumstances, a trigger for localized oxidative stress. iii) Redox reactions driven by intact ferric $\mathrm{Hb}$ (eg, ferryl species) could trigger a localized oxidative stress at endothelial-perivascular interface. iv) Free iron-driven oxidation reactions 

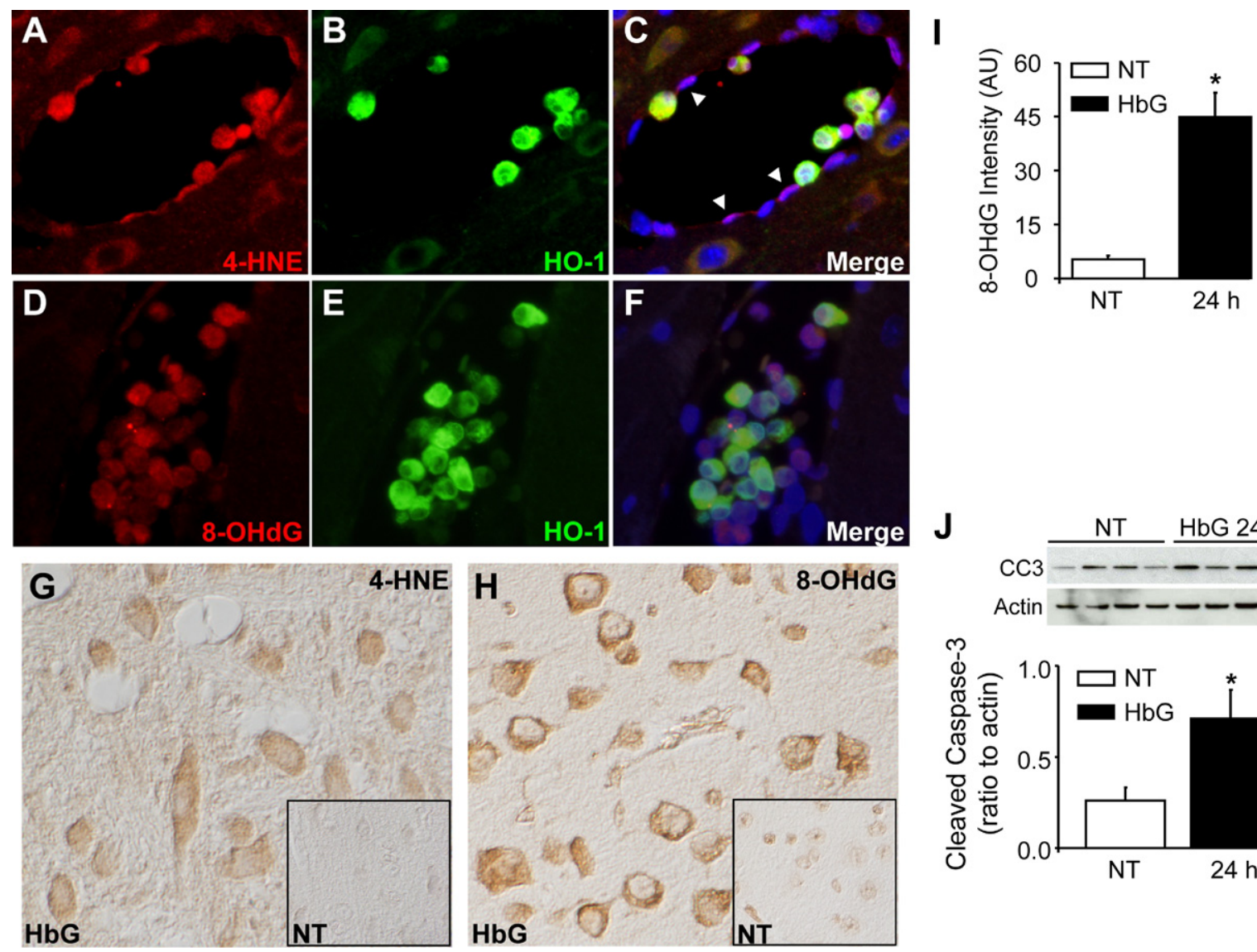

\section{$\mathbf{J}$}
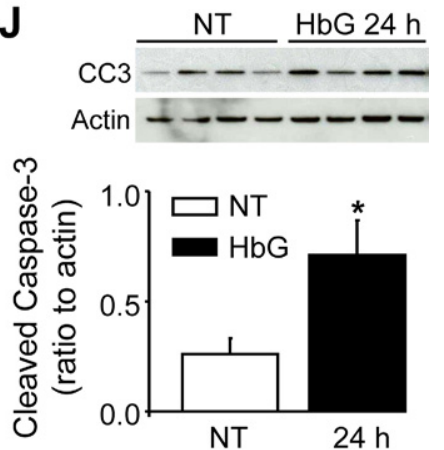

Figure 8. Oxidative markers, HO-1, and cleaved caspase 3 expression after HbG transfusion. Brain sections were stained with antibodies to HO-1, 4-HNEmodified adducts, and 8-OHdG and detected with relevant secondary antibodies conjugated with Alex Fluor 488 (HO-1, green) and Alex Fluor 555 (4-HNE and 8-OHdG, red) and counterstained with Hoechst 33342 (blue). HbG-transfused guinea pigs after 24 hours showing increased immunoreactivity for 4-HNE (A-C) and 8-OHdG (D-F) in endothelial cells (arrowheads) and co-localization with HO-1-positive cellular infiltrates. G and H: Immunohistochemical staining for 4-HNE-modified adducts $(\mathbf{G})$ and 8-OHdG $(\mathbf{H})$ in brain parenchyma of HbG-transfused guinea pigs after 24 hours. Inset images represent respective sham controls. In HbG-transfused animals, increased neuronal staining for 4-HNE and 8-OHdG was observed in cortical brain regions. Nuclear counterstain was omitted. I: Semiquantitative image analysis of 8 -OHdG staining intensity as described in Materials and Methods. Data were obtained from seven animals per group and presented as the means \pm SEMs. J: Western blot analysis of cleaved caspase 3 in sham controls and HbG-transfused guinea pigs. A representative Western blot is shown with each lane representing a separate animal. Data are expressed as a ratio to actin (mean \pm SEM; $n=4$ animals per group). ${ }^{*} P<0.05$ vs NT. Double-label epifluorescence microscopy; original magnification, $\times 400(\mathbf{A}-\mathbf{F})$. Differential contrast microscopy; original magnification, $\times 400(\mathbf{G}$ and $\mathbf{H})$.

may be involved. In support of the latter mechanism, we have found that administration of dexrazoxane (Zinecard), a commercially available iron chelator, immediately before HbG transfusion prevented the HbG-induced decrease in ZO-1 and attenuated the brain iron accumulation (see Supplemental Figure S3 at http://ajp.amjpathol.org). The protective effects of dexrazoxane in different models have generally been attributed to the compound's ironchelating properties; however, several studies have reported an additional protective mechanism by dexrazoxane associated with a non-chelating antioxidant function that may be more potent than typical small molecule reducing agents (eg, ascorbate, urate, and tocopherol) found circulating in plasma. ${ }^{57,58}$ Therefore, additional studies will be required to determine the precise mechanism of protection by dexrazoxane in the present setting.

BBB dysfunction associated with the "loosening" of TJs facilitates the entry of leukocytes into the brain parenchyma. For example, diminished ZO-1 expression has been shown to correlate with monocyte infiltration. ${ }^{59}$ In the present study, $\mathrm{HO}-1$ and CD163-positive infiltrates were identified in HbG-transfused animals. CD163, the putative monocyte/macrophage membrane receptor for $\mathrm{Hb}$-haptoglobin complexes, is mainly expressed on resident macrophages in the liver, spleen, lung, as well as perivascular/meningeal macrophages and pericytes in the CNS, and additionally peripheral blood monocytes but not on microglia. ${ }^{41,42}$ Our findings may be consistent with the previously reported findings that $\mathrm{Hb}$ and heme activate proinflammatory pathways leading to up-regulation of endothelial adhesion molecules, vascular cell adhesion molecule 1 and intercellular adhesion molecule 1, which promote leukocyte adhesion and transmigration. ${ }^{60,61}$ Activated monocyte/macrophages accumulating at the BBB interface could act as an important source of reactive oxygen/nitrogen species that could exacerbate the oxidative reactions of $\mathrm{HbG}$, heme, or iron.

BBB dysfunction and oxidative stress are common features of neurologic disorders, including cerebral ischemia, traumatic brain injury, and stroke. ${ }^{44,45}$ Besides the enhanced 4-HNE and 8-OHdG immunoreactivity associated with blood vessels in HbG-transfused animals, both markers were elevated in cortical neurons after 24 hours. This could be related, in part, to the greater sensitivity of 
neurons to heme- and iron-mediated toxicity compared with glial cells. ${ }^{62,63}$ Our observations that non-heme iron and oxidative markers accumulate in neurons provide preliminary evidence that systemic $\mathrm{HbG}$ exposure may affect other sensitive cells of the CNS. The precise temporal relationship between the HbG-mediated BBB events and the development of other CNS events will be important to delineate.

In summary, we report that systemic $\mathrm{HbG}$ exposure produces BBB disruption and oxidative stress in a guinea pig exchange transfusion model. These findings have potential implications in the area of $\mathrm{Hb}$-based oxygen therapeutics and may offer indirect insight into the mechanisms underlying the CNS vasculopathies associated with chronic or excessive hemolysis. ${ }^{11,12}$ Interestingly, the longer circulation half-life of $\mathrm{HbG}$ compared with native $\mathrm{Hb}$ (15 hours versus $\sim 1$ hour) does offer an experimental opportunity to evaluate how the BBB responds to a more sustained $\mathrm{Hb}$ exposure. $\mathrm{Hb}$ neurotoxicity with concomitant traumatic brain injury remains a concern in the $\mathrm{Hb}$ therapeutic field..$^{13}$ However, our present findings suggest that even in normal animals the interaction between systemic extracellular $\mathrm{Hb}$ and the BBB may have important acute consequences. These findings also suggest the need for a better understanding of $\mathrm{Hb}$ exposure and BBB function in disease state models of endothelial dysfunction whereby acute insults may lead to long-term pathologic events.

\section{Acknowledgments}

We thank Dr. Abdu Alayash for reviewing the manuscript and Dr. Eugene Herman (CDER/FDA) for critical discussions about dexrazoxane. We are thankful to Drs. Jaroslav Vostal and Xuan Chi (Laboratory of Cellular Hematology, CBER/FDA) for the use of the laser scanning confocal microscope.

\section{References}

1. Wagner KR, Dwyer BE: Hematoma removal, heme, and heme oxygenase following hemorrhagic stroke. Ann N Y Acad Sci 2004, 1012: 237-251

2. Robinson SR, Dang TN, Dringen R, Bishop GM: Hemin toxicity: a preventable source of brain damage following hemorrhagic stroke. Redox Rep 2009, 14:228-235

3. Keep RF, Xiang J, Ennis SR, Andjelkovic A, Hua Y, Xi G, Hoff JT: Blood-brain barrier function in intracerebral hemorrhage. Acta Neurochir Suppl 2008, 105:73-77

4. Prunell GF, Mathiesen T, Svendgaard NA: Experimental subarachnoid hemorrhage: cerebral blood flow and brain metabolism during the acute phase in three different models in the rat. Neurosurgery 2004, 54:426-436

5. Katsu M, Niizuma K, Yoshioka $\mathrm{H}$, Okami N, Sakata $\mathrm{H}$, Chan $\mathrm{PH}$ : Hemoglobin-induced oxidative stress contributes to matrix metalloproteinase activation and blood-brain barrier dysfunction in vivo. J Cereb Blood Flow Metab 2010, 30:1939-1950

6. Huang FP, Xi G, Keep RF, Hua Y, Nemoianu A, Hoff JT: Brain edema after experimental intracerebral hemorrhage: role of hemoglobin degradation products. J Neurosurg 2002, 96:287-293

7. Wang J, Doré S: Heme oxygenase-1 exacerbates early brain injury after intracerebral haemorrhage. Brain 2007, 130:1643-1652

8. Belcher JD, Beckman JD, Balla G, Balla J, Vercellotti G: Heme degradation and vascular injury. Antioxid Redox Signal 2010, 12:233-248
9. Buehler PW, D'Agnillo F: Toxicological consequences of extracellular hemoglobin: biochemical and physiological perspectives. Antioxid Redox Signal 2010, 12:275-291

10. D'Agnillo F, Alayash Al: Redox cycling of diaspirin cross-linked hemoglobin induces G2/M arrest and apoptosis in cultured endothelial cells. Blood 2001, 98:3315-3323

11. Rother RP, Bell L, Hillmen P, Gladwin MT: The clinical sequelae of intravascular hemolysis and extracellular plasma hemoglobin: a novel mechanism of human disease. JAMA 2005, 293:1653-1662

12. Kato GJ, Hebbel RP, Steinberg MH, Gladwin MT: Vasculopathy in sickle cell disease: biology, pathophysiology, genetics, translational medicine, and new research directions. Am J Hematol 2009, 84:618625

13. Silverman TA, Weiskopf RB: Hemoglobin-based oxygen carriers: current status and future directions. Transfusion 2009, 49:2495-2515

14. Pamplona A, Hanscheid T, Epiphanio S, Mota MM, Vigário AM: Cerebral malaria and the hemolysis/methemoglobin/heme hypothesis: shedding new light on an old disease. Int J Biochem Cell Biol 2009, 41:711-716

15. Bunn HF, Nathan DG, Dover GJ, Hebbel RP, Platt OS, Rosse WF, Ware RE: Pulmonary hypertension and nitric oxide depletion in sickle cell disease. Blood 2010, 116:687-692

16. Elsayed NM, Gorbunov NV, Kagan VE: A proposed biochemical mechanism involving hemoglobin for blast overpressure-induced injury. Toxicology 1997, 121:81-90

17. Samadder NJ, Casaubon L, Silver F, Cavalcanti R: Neurological complications of paroxysmal nocturnal hemoglobinuria. Can J Neurol Sci 2007, 34:368-371

18. Vichinsky EP, Neumayr LD, Gold JI, Weiner MW, Rule RR, Truran D, Kasten J, Eggleston B, Kesler K, McMahon L, Orringer EP, Harrington T, Kalinyak K, De Castro LM, Kutlar A, Rutherford CJ, Johnson C, Bessman JD, Jordan LB, Armstrong FD: Neuropsychological Dysfunction and Neuroimaging Adult Sickle Cell Anemia Study Group. Neuropsychological dysfunction and neuroimaging abnormalities in neurologically intact adults with sickle cell anemia JAMA 2010, 303: 1823-1831

19. Butt OI, Buehler PW, D'Agnillo F: Differential induction of renal heme oxygenase and ferritin in ascorbate and nonascorbate producing species transfused with modified cell-free hemoglobin. Antioxid Redox Signal 2010, 12:199-208

20. Abraham NG, Kappas A: Pharmacological and clinical aspects of heme oxygenase. Pharmacol Rev 2008, 60:79-127

21. Schipper HM, Song W, Zukor H, Hascalovici JR, Zeligman D: Heme oxygenase- 1 and neurodegeneration: expanding frontiers of engagement. Neurochem 2009, 110:469-485

22. Turner CP, Bergeron M, Matz P, Zegna A, Noble LJ, Panter SS, Sharp FR: Heme oxygenase- 1 is induced in glia throughout brain by subarachnoid hemoglobin. J Cereb Blood Flow Metab 1998, 18:257-273

23. Koeppen AH, Dickson AC, Smith J: Heme oxygenase in experimental intracerebral hemorrhage: the benefit of tin-mesoporphyrin. J Neuropathol Exp Neurol 2004, 63:587-597

24. Panahian N, Yoshiura M, Maines MD: Overexpression of heme oxygenase- 1 is neuroprotective in a model of permanent middle cerebral artery occlusion in transgenic mice. J Neurochem 1999, 72:11871203

25. Guan L, Wen T, Zhang $Y$, Wang $X$, Zhao J: Induction of heme oxygenase-1 with hemin attenuates hippocampal injury in rats after acute carbon monoxide poisoning. Toxicology 2009, 262:146-152

26. Gong Y, Tian H, Xi G, Keep RF, Hoff JT, Hua Y: Systemic zinc protoporphyrin administration reduces intracerebral hemorrhage-induced brain injury. Acta Neurochir Suppl 2006, 96:232-236

27. Chen M, Regan RF: Time course of increased heme oxygenase activity and expression after experimental intracerebral hemorrhage: correlation with oxidative injury. J Neurochem 2007, 103:2015-2021

28. Hawkins BT, Davis TP: The blood-brain barrier/neurovascular unit in health and disease. Pharmacol Rev 2005, 57:173-185

29. Persidsky Y, Ramirez SH, Haorah J, Kanmogne GD: Blood-brain barrier: structural components and function under physiologic and pathologic conditions. J Neuroimmune Pharmacol 2006, 1:223-236

30. Kaur C, Sivakumar V, Zhang Y, Ling EA: Hypoxia-induced astrocytic reaction and increased vascular permeability in the rat cerebellum. Glia 2006, 54:826-839

31. Jensen MB, Finsen B, Zimmer J: Morphological and immunophenotypic microglial changes in the denervated fascia dentata of adult 
rats: correlation with blood-brain barrier damage and astroglia reactions. Exp Neurol 1997, 143:103-116

32. Guillemin GJ, Brew BJ: Microglia, macrophages, perivascular macrophages, and pericytes: a review of function and identification. J Leukoc Biol 2004, 75:388-397

33. Krueger M, Bechmann I: CNS pericytes: concepts, misconceptions, and a way out. Glia 2010, 58:1-10

34. Buehler PW, D'Agnillo F, Hoffman V, Alayash Al: Effects of endogenous ascorbate on oxidation, oxygenation, and toxicokinetics of cellfree modified hemoglobin after exchange transfusion in rat and guinea pig. J Pharmacol Exp Ther 2007, 323:49-60

35. Buehler PW, Boykins RA, Jia Y, Norris S, Freedberg DI, Alayash Al: Structural and functional characterization of glutaraldehyde-polymerized bovine hemoglobin and its isolated fractions. Anal Chem 2005 77:3466-3478

36. Kuang F, Wang BR, Zhang $P$, Fei LL, Jia $Y$, Duan $X L$, Wang $X, X u Z$, Li GL, Jiao XY, Ju G: Extravasation of blood-borne immunoglobulin G through blood-brain barrier during adrenaline-induced transient hypertension in the rat. Int J Neurosci 2004, 114:575-591

37. Maines M: Carbon monoxide and nitric oxide homology: differential modulation of heme oxygenases in brain and detection of protein and activity. Methods Enzymol 1996, 268:473-488

38. Carter P: Spectrophotometric determination of serum iron at the submicrogram level with a new reagent (ferrozine). Anal Biochem 1971 , 40:450-458

39. Meguro R, Asano Y, Odagiri S, Li C, Iwatsuki H, Shoumura K: Nonheme-iron histochemistry for light and electron microscopy: a historical, theoretical and technical review. Arch Histol Cytol 2007, 70:1-19

40. Okajima K: On the selective staining of the erythrocyte. Anat Rec 1916, 11:295-296

41. Balabanov R, Washington R, Wagnerova J, Dore-Duffy P: CNS microvascular pericytes express macrophage-like function, cell surface integrin alpha $\mathrm{M}$, and macrophage marker ED-2. Microvasc Res 1996, 52:127-142

42. Van Gorp H, Delputte PL, Nauwynck HJ: Scavenger receptor CD163, a Jack-of-all-trades and potential target for cell-directed therapy. Mol Immunol 2010, 47:1650-1660

43. Walter JK, Rueckert C, Voss M, Mueller SL, Piontek J, Gast K, Blasig IE: The oligomerization of the coiled coil-domain of occludin is redox sensitive. Ann N Y Acad Sci 2009, 1165:19-27

44. Allen CL, Bayraktutan U: Oxidative stress and its role in the pathogenesis of ischaemic stroke. Int J Stroke 2009, 4:461-470

45. Pun PB, Lu J, Moochhala S: Involvement of ROS in BBB dysfunction. Free Radic Res 2009, 43:348-364

46. Brooks TA, Hawkins BT, Huber JD, Egleton RD, Davis TP: Chronic inflammatory pain leads to increased blood-brain barrier permeability and tight junction protein alterations. Am J Physiol Heart Circ Physiol 2005, 289:H738-H743

47. Haorah J, Knipe B, Gorantla S, Zheng J, Persidsky Y: Alcohol-induced blood-brain barrier dysfunction is mediated via inositol 1,4,5triphosphate receptor (IP3R)-gated intracellular calcium release. J Neurochem 2007, 100:324-336

48. Rao RK, Basuroy S, Rao VU, Karnaky KJ Jr, Gupta A: Tyrosine phosphorylation and dissociation of occludin-ZO-1 and E-cadherin- beta-catenin complexes from the cytoskeleton by oxidative stress Biochem J 2002, 368:471-481

49. Lochhead JJ, McCaffrey G, Quigley CE, Finch J, Demarco KM, Nametz N, Davis TP: Oxidative stress increases blood-brain barrier permeability and induces alterations in occludin during hypoxia-reoxygenation. J Cereb Blood Flow Metab 2010, 30:1625-1636

50. Dokladny K, Ye D, Kennedy JC, Moseley PL, Ma TY: Cellular and molecular mechanisms of heat stress-induced up-regulation of occludin protein expression regulatory role of heat shock factor-1. Am J Pathol 2008, 172:659-670

51. McCaffrey G, Staatz WD, Quigley CA, Nametz N, Seelbach MJ, Campos CR, Brooks TA, Egleton RD, Davis TP: Tight junctions contain oligomeric protein assembly critical for maintaining blood-brain barrier integrity in vivo. J Neurochem 2007, 103:2540-2555

52. Chen-Roetling J, Benvenisti-Zarom L, Regan RF: Cultured astrocytes from heme oxygenase- 1 knockout mice are more vulnerable to hememediated oxidative injury. J Neurosci Res 2005, 82:802-810

53. Regan RF, Guo Y, Kumar N: Heme oxygenase-1 induction protects murine cortical astrocytes from hemoglobin toxicity. Neurosci Lett 2000, 282:1-4

54. Matz P, Turner C, Weinstein PR, Massa SM, Panter SS, Sharp FR: Heme-oxygenase-1 induction in glia throughout rat brain following experimental subarachnoid hemorrhage. Brain Res 1996, 713:211222

55. Beschorner R, Adjodah D, Schwab JM, Mittelbronn M, Pedal I, Mattern R, Schluesener HJ, Meyermann R: Long-term expression of heme oxygenase-1 (HO-1. HSP-32) following focal cerebral infarctions and traumatic brain injury in humans. Acta Neuropathol 2000 100:377-384

56. Bunn HF, Jandl JH: Exchange of heme among hemoglobins and between hemoglobin and albumin. J Biol Chem 1968, 243:465-475

57. Hasinoff BB, Hellmann K, Herman EH, Ferrans VJ: Chemical, biological and clinical aspects of dexrazoxane and other bisdioxopiperazines. Curr Med Chem 1998, 5:1-28

58. Galetta F, Franzoni F, Cervetti G, Regoli F, Fallahi P, Tocchini L, Carpi A, Antonelli A, Petrini M, Santoro G: In vitro and in vivo study on the antioxidant activity of dexrazoxane. Biomed Pharmacother 2010, 64: 259-263

59. Boven LA, Middel J, Verhoef J, De Groot CJ, Nottet HS: Monocyte infiltration is highly associated with loss of the tight junction protein zonula occludens in HIV-1-associated dementia. Neuropathol Appl Neurobiol 2000, 26:356-360

60. Silva G, Jeney V, Chora A, Larsen R, Balla J, Soares MP: Oxidized hemoglobin is an endogenous proinflammatory agonist that targets vascular endothelial cells. J Biol Chem 2009, 284:29582-29595

61. Wagener FA, Feldman E, de Witte T, Abraham NG: Heme induces the expression of adhesion molecules ICAM-1, VCAM-1, and E selectin in vascular endothelial cells. Proc Soc Exp Biol Med 1997, 216:456-463

62. Gaasch JA, Lockman PR, Geldenhuys WJ, Allen DD, Van der Schyf CJ: Brain iron toxicity: differential responses of astrocytes, neurons, and endothelial cells. Neurochem Res 2007, 32:1196-1208

63. Goldstein L, Teng ZP, Zeserson E, Patel M, Regan RF: Hemin induces an iron-dependent, oxidative injury to human neuron-like cells. J Neurosci Res 2003, 73:113-121 